\title{
The Safety City Program: knowledge is power
}

\author{
Ilona Lubman
}

Safety City is a full scale street and intersection constructed in central Harlem in 1989 by the New York City Department of Transportation (NYCDOT). It includes real traffic and pedestrian signals, street signs, pavement markings, and street furniture. Perimeter fencing protects third graders (age 8) while they practice crossing the street and driving a bicycle in a changing physical and social environment.

NYCDOT professionals work alongside community health care providers and police officers, traffic agents, and school crossing guards from the local precinct during two four hour sessions of on-site instruction as well as classroom visits before and after children attend Safety City. Senior high school students (ages 15-18) serve as assistants, and graduates of the program return as interns and volunteers. A traffic safety musical theater performance, which introduces and reinforces the concepts taught at Safety City, is attended by kindergarten through fifth graders (ages 5-11) at schools, camps, and parks throughout Northern Manhattan (including Harlem and the area directly north). Safety City staff are usually noticeable at neighborhood health fairs and festivals.

The Harlem Hospital Injury Prevention Program (HHIPP), a coalition of government and community organizations, provides safe places and activities for children during after school hours. This partnership is an essential component of the Safety City Program.

In the three years after the inception of the Safety City Program, motor vehicle related injury to central Harlem children aged 5-16, the targeted group, was reduced by $55 \%$. During the same time period, there was no change in non-targeted injuries. ${ }^{1} \mathrm{~A}$ more recent evaluation has shown that during the six years after Safety City Program intervention, for Northern Manhattan as a whole, there has been a $35 \%$ reduction in the rate of all traffic injuries to schoolchildren and a $40 \%$ reduction in the rate of severe pedestrian injuries - from 127.15 per 100000 population in 1988, before the Safety City Program, to 76.51 per 100000 in 1995. There has been no comparable reduction for non-targeted injuries. ${ }^{2}$ Injury control advocates and educators are now coming to us
New York City Department of Transportation, 40 Worth Street, New York, New York 10013, USA

Correspondence to: Dr Lubman, Director of Safety Education.

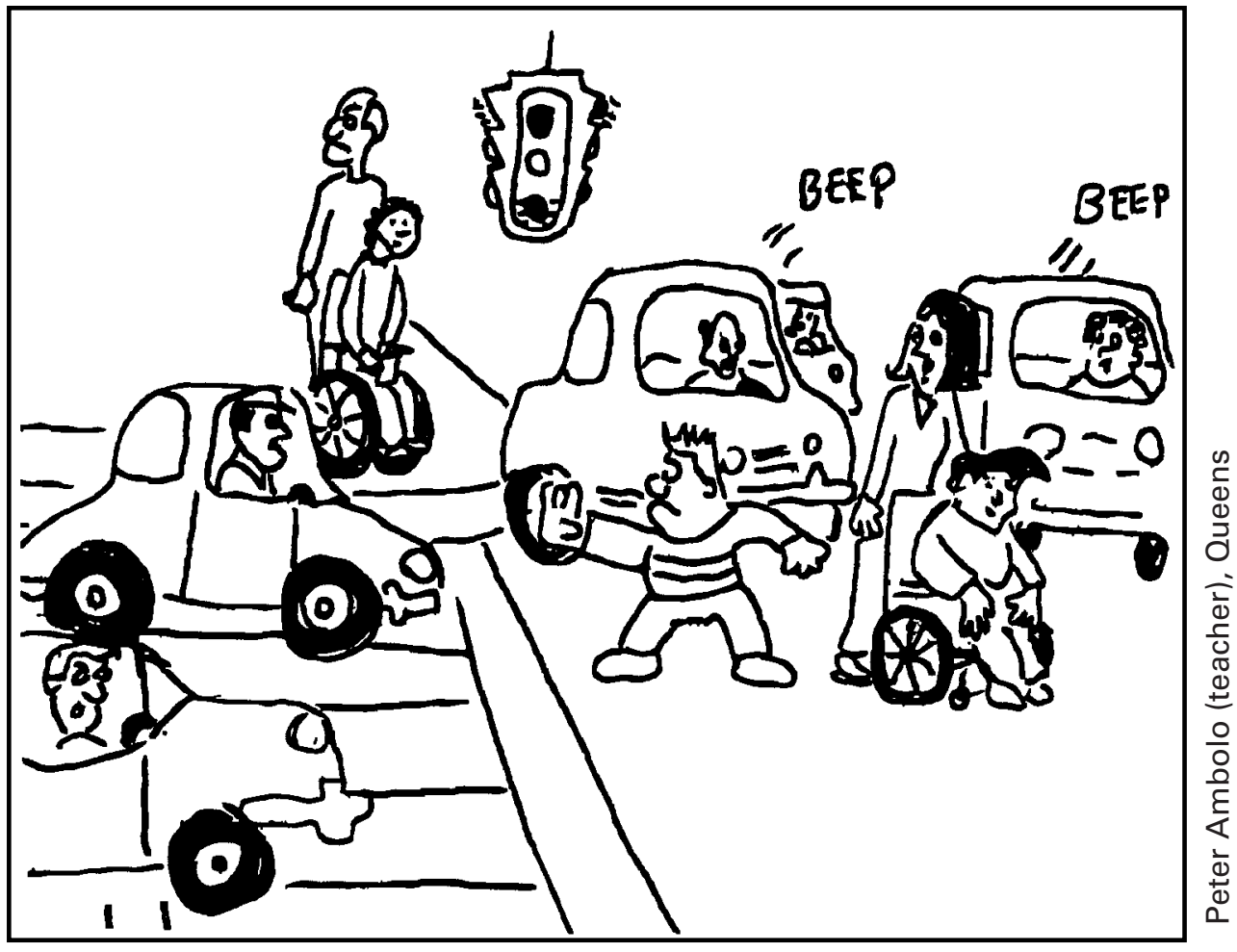

Figure 1 Children with physical impairments relate to their artist-teacher "what it's like for me to cross the street". 


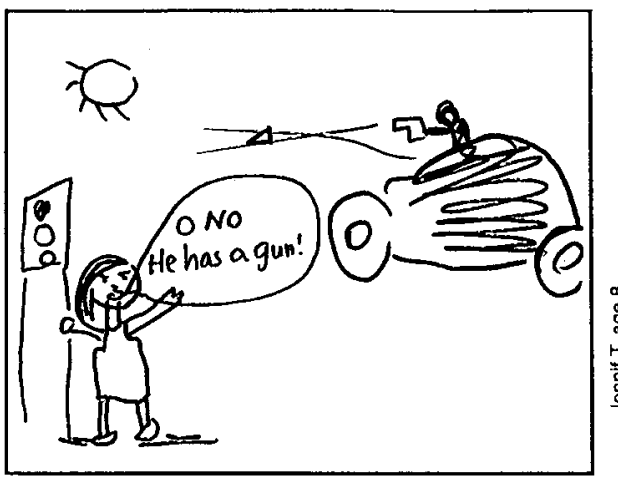

Figure 2 Getting safely from point $A$ to point $B$ may require accommodating unexpected social realities.

asking: What is the Safety City curriculum and how can we get the Safety City Program to work in our community?

The Safety City Program was developed from an anthropological perspective, which is to say we set out to understand what was going on in the area before we decided what to do about it. This meant, to the extent possible, that we had to strip ourselves of the familiar traffic safety propaganda long time safety educators recite like mantras to the public and to other "safety experts". We began with the premise that behavior cannot be understood apart from its context. Instead of allowing ourselves to observe and make judgments about what people do, we asked "What are the circumstances under which I might do that?"

(1) Stop, look, listen

Before developing the Safety City curriculum we reviewed existing materials and observed instruction. We watched and listened to children at play and on their way to and from school.

The setting for virtually all early childhood traffic safety materials is some make believe place where real people don't walk or drive or face the real challenges of getting around. The environments portrayed are one dimensional: a car with a driver stopped at a signal waiting patiently for a child with a smiling parent and a smiling dog to cross. Life is predictable: no conflict, no decision to be made. No drunk drivers. Mom is always there to lend a hand when the pedestrian signal says WALK and when the ball rolls into the street, and of course Mom is sober!

In short, curriculum materials teach children to cross streets safely in a place that doesn't exist, certainly not in a multicultural urban area. A third grade critical thinker from the Bronx said it succinctly: "It ain't like that".

Several interesting themes recur:

- The traffic world is seen and taught from the driver's perspective. Even though children cross the streets as pedestrians (WALK/DON'T WALK), they are taught the driver's chant: "Red light means sTOP, green light means GO ....”. (Note: drivers are the dominant culture and children are socialized to identify with the mode that wields the greater power in the hierarchy of road users.)

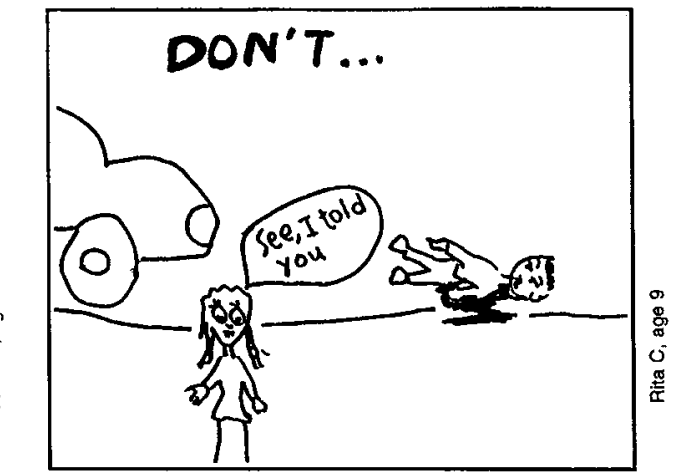

Figure 3 Children's artwork oozes with the residue of lessons based on fear and blame rather than knowledge.

Implicit in materials and instruction is the notion that drivers and traffic controls have more control than they actually have (for example that drivers will always stop at a red light) and that pedestrians (children and other subordinates in the road user hierarchy) have less control than they actually have. Moreover, when drivers make mistakes they have protections; mechanisms of forgiveness (airbags, safety belts) are built in. Therefore, it is not surprising that laws notwithstanding, most pedestrians are conditioned to yield to turning drivers.

- A good deal of what is taught contradicts what traffic safety experts and professionals in other disciplines know to be true. For example, we know that young children are at highest risk as pedestrians because, among other things, they think cars can (and will) stop instantly and that cars are "friendly". Yet video characters like Otto the Auto, an adorable little talking car with big blue headlight eyes that make you want to pull him close and cuddle up, have, for years, been popular aids in teaching the dangers of getting close to cars.

Children are taught that there is safety in numbers - brawn over brain. Yet, what we generally observe when a group of people, including strangers, cross together is that individuality is subsumed by the herd (that is, the herd is the authority). The walker slips into a passive role, tuning out critical safety cues he is more sensitive to when traveling solo. The individual becomes part of the traveling collective consciousness-more like passenger (victim) than driver.

- Traffic safety is taught as gospel; conventional morality is a subtext. There is one right way to do things. Certain commandments, like "Cross at the green, not in between" are passed along on faith and lots of information is framed in terms of what not to do: "Don't cross the street in the middle of the block", "Don't play in the street" ... Should you do a Don't, something bad will happen to you that you have brought upon yourself.

What children (and others) report after witnessing a crash is akin to a description of a sports event. Often the first thing they do is pick the "good guy and the bad guy", somebody to throw their emotional support behind and somebody else to assign blame (for example "It was his own fault ...", "He wasn't 
even looking...”). Rarely does an account include statements of shared responsibility.

- Obey is used a lot: information given to parents instructs them to teach their children to obey all traffic signals. Children are told to obey the crossing guard, bicyclists to obey the rules of the road and so forth. (Note: though obedience training does have advantages for pets with whom we want to develop a relationship of greater dependency, the benefits of obedience training for those facing less predictable social and physical environments are questionable.)

STOP

When we teach compliance are we teaching safety? Does the traditional safety curriculum conform to "common sense" notions of what is safe or is it formed by the data? Let's take a look.

LOOK

In 1988 , when we started thinking Safety City curriculum, $64 \%$ of all pedestrian injuries or fatalities in New York City occurred at intersections; $50 \%$ of these were intersections with traffic signals. Sixty per cent of pedestrians injured or killed at signalized intersections were crossing with the signal in their favor. ${ }^{3}$ (The most recent 1996 data are similar, with $65 \%$ injured or killed crossing with the signal. ${ }^{4}$ ) For children aged 5-14 injured or killed at intersections with traffic signals, $41 \%$ were crossing with the signal (45\% in 1996).

So much for teaching safety by cliché. These data put "cross at the green" in a new light. Even if we know where to find our right-of-way, it does not serve us to assume others will yield to it.

LISTEN

When we teach compliance are we compromising safety?

LOOK LEFT, RIGHT, LEFT

Traffic safety "education" has its roots in enforcement-historically, police and crossing guards have been its symbols and instructors. Think about it: enforcement is about preserving the status quo, restating the boundaries, reminding us who and what is important; conversely, the educational process involves questioning authority, learning the limits and then thinking beyond them, embracing what is unique. In the world of traffic safety, education is often interpreted to mean information, and it is usually the assignment of "educators" to create and deliver messages from an enforcement point of view, emphasizing laws and sanctions for non-compliance.

From an enforcement perspective, traffic signs and signals and other things that get enforced operate in isolation of other social and environmental signals (for example construction in the crosswalk, drug sales at the corner). Children are taught to subordinate their judgment (processing environmental cues) to the traffic control (authority).

BE ALERT

Traffic safety, of course, is about much more than traffic: the busy city streets are a constant

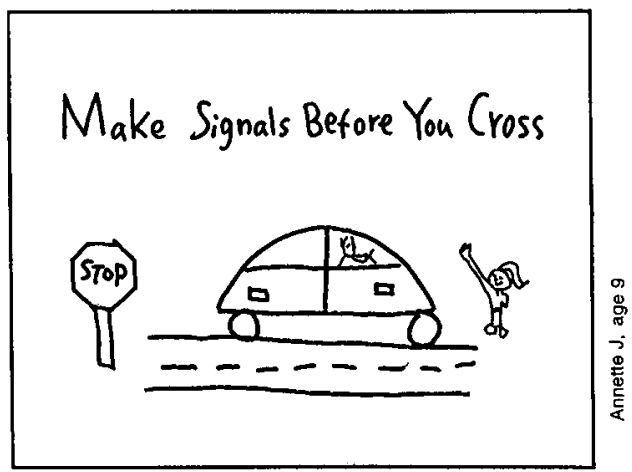

Figure 4 Assertion skills help pedestrians appreciate the integrity of the mode they control.

whirl of sound, smell, color-many frames at a time and on fast forward. Drug abuse and aggression are expressed as driving while intoxicated and aggressive driving. Always there are reminders that personal fate is linked with the fate of strangers competing for scarce space for different purposes. Therefore, we need to expect the unexpected and be as prepared as possible for it.

Given that context, we began to build a program based in reality rather than expediency or tradition. We tilted the emphasis from the short term educational benefits of enforcement to the long term self enforcement benefits of education. Rather than asking "How can we get children to know and comply with traffic laws?" we started by asking "What works to protect children from injury and death?”

\section{(2) Developing survivors, not victims} LEARNING TO ENGINEER SAFER SOLUTIONS

At Safety City, children learn that they have a legitimate place in their environment, no less important than other road users. No false consciousness, no toy cars. Driving is serious and they are drivers - of their bicycles and of their bodies. They are powered by their brain and their safety depends on their ability to understand the symbols relevant to the modes they control (for example, how many times does the DON'T WALK signal flash before it changes to a solid DON'T WALK? What do the bars in a crosswalk mean?). There are cars and trucks on the street that they interact with, come into conflict with, yield to, and which may yield to them. They learn assertion skills, called power words and behaviors. These include holding their hand up high as they cross, making eye contact with drivers, continuing to scan as they cross, wearing reflective material. These behaviors let others know their expectations: they insist on being seen and are active agents in protecting their right to safety.

Children learn to be better problem solvers by knowing different points of view and discovering how they connect with their own. When a child sits in the cab of a large truck, she sees the world from the truck driver's perspective. She learns how far to walk in front of the truck in order to be seen. Other exercises, like changing roles as an escort/blindfolded classmate when crossing the street, help children learn to anticipate, compensate, assist, and be assisted 


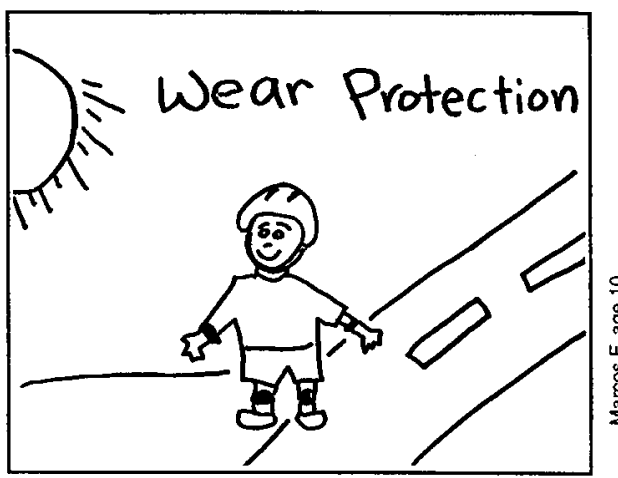

Figure 5 Through role playing, children practice intervention techniques - providing accurate information, showing concern, setting an example-to encourage others to make safer choices.

by those with different needs/capabilities in their shared environment.

DEMYSTIFYING SIGNALS AND OTHER SYMBOLS

A signal is a message of warning, encouragement or other information used to make decisions. When they become safety detectives children internalize the adult's "be alert" command, continuously collecting and scanning for sensory clues. The teacher might start by asking, "What are signals it is lunch time?" The physiological, environmental, and social "data" they collect might include: my stomach is growling, the clock says noon, the boy next to me has closed his book... Each signal provides a clue with more or less value, depending on the other signals that accompany it. Children learn that crosswalks are safer places for pedestrians because that's where drivers expect to see them. But what if, let's say, a group of older kids is pushing and yelling at that corner? Might this be an overriding signal to reevaluate an earlier decision to "GO" there?

TOOLS NOT RULES

Children visit Safety City twice. The first visit's theme is "Things I can say and do to be safer" (assertion/intervention, street crossing techniques, environmental signals); their second trip is organized around "Things to wear to be safer" (helmets, reflective clothing, safety belts). Both are designed to have application in all spheres of the child's life and extend to lessons beyond third grade-academic (critical thinking), personal (my responsibility to myself), and social (my responsibility to my community). Traffic safety is taught literally to third graders but its symbols are metaphors that can later be generalized to other preventive behavior (that is, both a helmet and a condom are "Things to wear to be safer" and both involve a choice that impacts on self and community, but the former can be discussed without the same moral baggage). And the more ways a child can use the Safety City concepts in other decision making contexts, the more traffic safety lessons will be reinforced.

Many traffic safety rules are dissonant with the experience of many children, particularly those at highest risk. For example, when we say "Hold Mom's hand when you cross the street", we are saying more about the value put on traditional family configuration than on safety. In class, children will repeat, in unison, "I will hold a grown-up's hand when I cross the street" even when we observe few adult escorts at school dismissal. If follow through is not feasible, repetition of rules fosters a sense of defeat and alienates the child from the information being taught and the person teaching it. (It is interesting to note that when Safety City was expanded to Staten Island, a more homogeneous area with a disproportionate number of adults who have careers in law enforcement, there was a call to modify the curriculum to emphasize rules rather than tools.)

DEVELOPING PRODUCERS, NOT JUST CONSUMERS OF INFORMATION

Rather than talk rules at the children, Safety City instructors guide them in the process of finding their own realistic solutions; they help them discover the inventory of their "safety tool box". Children look for the resources they do have-tools shared by the community (signals, crosswalks, parks, playgrounds, etc), personal tools (eyes, ears, feet, hands, brain, etc), and interpersonal or social tools (family, friends, teachers, choir, scouts, etc). Each tool box is unique, because each of us is unique with special strengths and circumstances. It is important that children claim what is theirs. Some of their tools are powerful, others in disrepair, some they haven't yet learned to use, others they will need to acquire. It is the way we combine and care for our tools that creates our advantage. Teachers encourage the search. The child continues to reach in and out of his toolbox to engineer safer choices, at the same time nurturing an appreciation of what he does have and what he can do-his own endless possibilities.

The interaction is empowering for the instructional team of educators, police officers, enforcement agents, and volunteers from the community as well. By listening to the children, they gain information and motivation to advocate for environmental and other enhancements. The command "Don't play in the street" becomes a more reasonable one when safer alternatives are available. From 1989 to 1995, the HHIPP built 25 new playgrounds in central Harlem parks and schools. The Department of Parks refurbished all playgrounds in Northern Manhattan parks with fenced perimeters that prevent children from running into the street. Many of these playgrounds have sprinklers, an alternative to cooling off around open fire hydrants (and cars). The HHIPP also conducted supervised after school recreational and arts programs.

The NYCDOT, through its driving while intoxicated community service program, assigned people to work off their sentences by cleaning the Safety City streetscape and packaging/delivering materials to schools. NYCDOT provided a safety theater production and puppet shows to elementary schools, and in parks and community centers throughout Northern Manhattan. Materials were distributed at these performances and at pediatric 
clinics and health fairs for children to share with family, friends, and neighbors.

Later, NYCDOT implemented Manhattan's first residential safety zone where all defective traffic signals and streetlights around Safety City were repaired and high visibility signs and markings were installed. The Police Department conducted selective enforcement of speeding, red light running, and passing a stopped school bus.

MY COMMUNITY AND ME: A RECIPROCAL RESPONSIBILITY

Prior to the first visit, the Safety City instructor attends the home school to let the class know what to expect from the program and to survey the surrounding area. The classroom teacher is provided a teacher's guide with exercises to prepare for and reinforce the concepts introduced at Safety City. The teacher learns how the exercises can be used to enhance required curriculum in areas including language arts, science, mathematics, and social studies. As well, she is given "Safe City Rap", a lively video with singalong traffic safety raps and dances performed by Safety City graduates and professionals. She is asked to sign a letter of commitment to schedule follow up activities (poems, artwork, essays, cartoons, songs) to contribute to YES: A Magazine By and For NYC Kids or enter in the traffic safety calendar contest. These publications extend the boundaries of the students' community and the range of their voice since thousands are distributed by the NYCDOT citywide to schools, libraries, hospitals, community centers, and shelters. The children learn how, by sharing what they learn, they will earn a Safety Deputy pin and certificate, signs of their special status and reminders of the responsibilities that go along with it.

The first recommended pre-visit activity is to write a letter to a parent/caregiver informing them of the trip, using phrases like "At Safety
City I will learn about..." and "After the visit I will share with you information about how to ...". The next is to adopt a group (some opt for peers, others prefer to serve as mentors to a class of younger children, one class adopted a senior center across the street) to share information and materials they take from Safety City. The instructor leaves with original name tags the children have made that he personally distributes at their first visit. This provides continuity and welcomes them with the dignity and a sense of responsibility that come with having one's individuality acknowledged. The stage is set for learning.

As children travel beyond the third grade they will come face to face with decisions that carry many more layers of meaning and consequence. The more adept they become at using their tools, the more power they will have to rely on their own devices, protect themselves in the absence of authority, and intervene on behalf of others. The countless rehearsals of STOP (and think about where I want to go), LOOK (gather accurate information about my options and the short and long term consequences of taking various paths), and LISTEN (assess and reassess benefits and trade-offs as I go) will have prepared them to confidently stand apart from the herd. Whatever road Safety City graduates choose, the skills they have been introduced to at Safety City will help keep them safer in traffic, and other decision making circumstances, for a lifetime.

1 Laraque D, Barlow B, Durkin $\mathrm{M}$, et al. Injury prevention in an urban setting. Bull N Y Acad Med 1995;72:27-9.

2 Durkin MS, Laraque D, Lubman I, et al. Epidemiology and prevention of severe traffic injuries to children in an urban community. Pediatrics 1999;103(6): June (electronic pages).http://www.pediatrics.org/cgi/content/full/103/6/e74

3 Summary of motor vehicle accidents in New York City MV 144- $A$. New York: State of New York Department of Motor Vehicles, 1988: 4.

4 Summary of motor vehicle accidents in New York City MV 144-A. New York: State of New York Department of Motor Vehicles, 1996: 4. 